\title{
A new method for measurement of annual growth rings in cork by means of autofluorescence
}

\author{
P. Surový • A. Olbrich · A. Polle · N. A. Ribeiro • \\ B. Sloboda $\cdot$ R. Langenfeld-Heyser
}

Received: 27 November 2008 / Accepted: 15 June 2009/Published online: 7 July 2009

(C) The Author(s) 2009. This article is published with open access at Springerlink.com

\begin{abstract}
A new method for measuring annual growth rings in cork has been developed. It is based on the fact that excitation of Quercus suber L. cork cross-sectional planes with UV light and also with blue light results in enhanced autofluorescence at the growth ring borders. This distinct autofluorescence band is located in the cork produced at the end of the vegetation period, with its smaller cells and thicker cell walls. The enhanced autofluorescence of polyphenolics mainly results from a very thick suberin layer in the walls of the small late cork cells. The gradient in autofluorescence from late cork to first early cork is steep. The best visibility of cork annual rings was found under the epifluorescence microscope in $60 \mu \mathrm{m}$ thick microtome cork cross sections. For fast screening of high sample numbers scanning the blue-excited $(473 \mathrm{~nm})$ fluorescence of water wetted polished cross-sectional surfaces of cork pieces with a laser-equipped fluorescence image
\end{abstract}

Communicated by H. Pfanz.

P. Surový · N. A. Ribeiro

Departamento de Fitotecnia, Universidade de Evora,

Apartado 94, 7002-554 Evora, Portugal

A. Olbrich · A. Polle $\cdot$ R. Langenfeld-Heyser $(\bowtie)$

Büsgen Institute, Forest Botany and Tree Physiology,

Georg August University of Göttingen, Büsgenweg 2,

37077 Göttingen, Germany

e-mail: rheyser@gwdg.de

P. Surový · B. Sloboda

Büsgen Institute, Ecoinformatics, Biometrics and Forest Growth,

Georg August University of Göttingen, Büsgenweg 4,

37077 Göttingen, Germany

P. Surový

Instituto Superior de Agronomia, Universidade Tecnica de Lisboa, Tapada da Ajuda, 1349-017 Lisboa, Portugal analyzer was most suitable. Evaluation of visibility of cork rings showed a clear improvement in comparison with reflected light image analysis; thus data obtained with this new autofluorescence scanning method are excellent for modeling the yearly growth increment of cork.

Keywords Cork - Quercus suber L. .

Annual growth rings $\cdot$ Autofluorescence

\section{Introduction}

Cork is a specific forest product, the bark extracted from Cork Oak (Quercus suber L.) that is widely grown in different countries in the western Mediterranean area. The cork product market was estimated to be around 1 billion US dollars a year (Gonçalvez 2000), thus information about cork productivity is of high importance. Several studies were carried out to provide estimations of cork growth and of the factors that can influence it, e.g., precipitation, temperature, competition, etc. Montero et al. (1996) and Caritat et al. (1996) studied annual growth. Tomé et al. (2001) and Ribeiro et al. (2003) modeled and described cumulative growth of cork.

One of the reasons why cumulative growth is modeled instead of annual growth is the fact that normally the annual rings are difficult to delineate. For example, Caritat et al. (1996) measured annual rings, but $20 \%$ of the samples of the largest time series dataset had to be rejected because of technical reasons. In another time series, they used 11 and 13 samples to evaluate the ring width; to obtain good visibility of the rings, they had to boil the cork samples for $40 \mathrm{~min}$ prior to thin slicing for investigation under the binocular microscope; it is obvious that this method is accurate but time consuming. 
Analyzing cork cross-sectional planes in the scanning electron microscope Pereira et al. (1987) observed that the cell dimensions of late cork cells are smaller and their cell walls thicker than in early cork cells. In addition they found a heavy corrugation and collapsing of the thin walled early cork cells directly adjacent to the previously formed late cork cells. Fortes et al. (2004) stated that annual rings of cork are formed similar to those in wood: the number of cells per volume unit is higher in autumn; the resulting cork color is darker than earlier in the season. Indeed annual rings from conifers (e.g., Picea abies, Müller et al. 2003; Wimmer 2002), but also from wood of Quercus suber (Quilho et al. 2003) show big, thin walled early wood cells and radially flattened thick-walled latewood cells. The boundaries are always marked by size differences between latewood and early wood, however, distinctness and structure of the annual ring boundaries are species specific (Schweingruber 1988); in ring-porous wood e.g., delineation of the growth ring border is mainly due to the extreme width of the first formed early wood vessels as compared to the smaller width of the late wood vessels (Schweingruber 1988; Evert 2006; e.g., in Fraxinus, Kitin et al. 2004). Fortes et al. (2004) concluded that a similar construction of growth ring borders in cork as in wood of certain species should allow the observation of the annual growth of cork in a similar way as in wood. Nevertheless the authors also conceded that the delineation of individual years is not always obvious, thus causing sometimes difficulties to study the annual cork growth. Growth rings in wood have to be either observed in sections or polished cross-sectional surfaces under a low magnification microscope (Schweingruber 1988) or differences in wood density are used to delineate the growth ring borders. For this, cross-sectional planes are analyzed by radiodensitometry (Schweingruber 1988, 1990) or wood density is measured as a function of the intensity of reflected light, the brightness of the growth rings (Park and Telewski 1993; Sheppard and Graumlich 1996). Scanner based image processing tree ring measurement systems (Guay et al. 1992, Sheppard and Graumlich 1996) are used for analysis of annual rings in wood. Also in cork one of the common methods for the evaluation of annual growth rings is the use of digital image analysis (Neves 2001). Image analysis is also used for cork quality evaluation (Pereira et al. 1996). To measure annual rings on a cork sample, measurements have to be conducted along several radial transect lines across the cork cross-sectional plane, which could easily be done on scanner based images. Measurements have to be repeated because the annual rings are not always parallel with the cork cambium due to the irregular cork surface, resulting in variability of thickness in annual rings (Fortes and Rosa 1992). Thus, a measurement along a single transect on a sample is unrepresentative. This renders measurements of cork oak annual ring growth time consuming.
For modeling, larger sets of only high-quality observational data are required. In a preliminary analysis two sets of 694 and 508 cork samples, respectively, were used for the delineation of individual growth rings by independent evaluators (Surovy unpublished). After the delineation of the growth rings on visible light scans, the evaluators were asked to classify for each measurement the visibility of the rings according to the following ranking system: very good, good, bad, very bad. Only in $10 \%$ of the cases, the evaluators were completely sure about the localisation of all the growth rings (rank: very good) and in 30-60\% of the cases, rings were detected, but whether these rings represented annual rings was not completely certain (rank: good); about $50 \%$ of the samples were classified as bad or very bad. Apparently, only $10 \%$ of the data could be used for modeling with full confidence. To overcome this problem, novel methods affording the detection of annual rings in cork with high reliability would be desirable. Methods other than visible light scanning that are more presice and widely used in delineation of growth ring borders in wood, however, seem to be too time consuming for obtaining larger sets of high-quality data from cork growth for modeling.

In the present study, we have, therefore, tested fluorescence techniques to identify annual growth rings in cork with high precision and to evaluate their biochemical basis. The main goal was to develop a method suitable for rapid and accurate identification of growth rings in cork.

\section{Materials and methods}

\section{Cork samples}

Cork from 30 trees was obtained in 2004 from Coruche $\left(39^{\circ} 05^{\prime} \mathrm{N},-08^{\circ} 41^{\prime} \mathrm{E}\right)$, Portugal, where permanent research plots are maintained by University of Évora. A larger cork piece was removed from the west side of cork oak (Quercus suber) stems at $1.3 \mathrm{~m}$ height (Ribeiro et al. 2003). The fresh cork was dried under ambient conditions. The last cork harvest in the plot used for the present investigation was carried out in 1994. The cork used here was, therefore, 10-years-old (nine full years and two half years of growth). For purposes of the present study this means that 10 lines of autumn cork and nine complete annual rings should be present.

Radial cork strips (64 from 30 trees) used for growth evaluation by means of image analysis were ca. $3-4 \mathrm{~cm}$ thick in axial direction, about $2 \mathrm{~cm}$ wide, and smoothened on their cross-sectional surfaces by a fine polishing paper (PS 30D, K 240; Klingspor, Haiger, Germany). For scanning of cork pieces with a fluoro imager, cork samples had to be thinned to $2.5-\mathrm{cm}$ maximum thickness, with the 
cross-sectional surface either polished by fine polishing paper (PS 30D, K 240) or smoothened with a microtome knife profile "c" (Reichert-Jung, Leica Instruments, Nußloch, Germany).

\section{Microtome sections}

For microscopic studies and also for some studies using the Fluoro Image Analyzer pieces of cork were cross sectioned with a sliding microtome (Reichert, Vienna, Austria) using a microtome knife with profile "c". The thickness of the cross sections was about $60 \mu \mathrm{m}$; thinner sections were difficult to obtain due to the elasticity of the cork. The cork cross sections were mounted in glycerol, with or without staining, on a glass slide and covered with a cover glass.

Detection of annual rings with normal light and by autofluorescence

Images to investigate growth ring borders were obtained by scanning polished cross-sectional surfaces of cork pieces with a HP ScanJet 4850 (Hewlett Packard, Palo Alto, California, United States).

Autofluorescence of growth ring borders was evaluated in cork cross sections mounted in $70 \%$ glycerol and investigated in an epifluorescence microscope (Zeiss, Axioplan, Oberkochen, Germany). Two types of Zeiss filter combinations (exciter filter, beam splitter, long wave pass filter) were used to find out the best excitation wavelength: (1) Ultraviolett: G 365, FT 395, LP 420, (2) Blue: BP 450-490, FT 510, LP 520. A radial series of six microphotographs (from years 1994 to 2004) was taken at $125 \times$ microscope magnification with a digital camera (Nikon Coolpix 4500, Nikon, Tokyo, Japan). The serial images were combined to a complete scan by software Adobe Photoshop CS2 (San Jose, California, USA).

Both glycerol mounted cork cross sections and cork pieces with polished cross-sectional planes were investigated for annual growth ring lines with a laser based fluorescence imager (Fluoro Image Analyzer FLA -5100; FUJIFILM, Life Science USA, Stamford, CT 06092 and software Aida v. 4.10; raytest, Straubenhardt, Germany). This instrument employs solid-state lasers of wavelengths suitable for excitation of fluorescent compounds. The recording surface is scanned with a 473-nm laser beam and emits fluorescent light. This light is detected by a photomultiplier tube (PMT) and converted to electric signals following the above mentioned settings. The gradation selected was $0-65536$ corresponding to 16 bit depth. The spatial resolution was $10 \mu \mathrm{m}$.

For investigation of cross-sectional planes of cork pieces with the Fluoro Image Analyzer, three different scanning procedures were performed: (1) scanning of sand paper polished cross-sectional planes just weighted down by a cube of lead to permit full contact with the glass table, (2) scanning of sand paper polished and wetted cross-sectional planes employing water as contact material, and (3) scanning cross-sectional planes which had been carefully smoothened with a microtome knife to be completely straight.

Visibility of growth ring border-structural basis

Cork cross sections mounted in $70 \%$ glycerol were observed under both a light and fluorescence microscope. Microphotographs were taken with a Nikon Coolpix 4500 digital camera to show structural differences between summer and autumn cork.

Visibility of growth ring border-chemical basis

Different staining methods were used on cork microtome cross sections to find out the chemical basis of the differential autofluorescence of growth ring borders in the fluorescence microscope and to find out whether the visibility of growth ring borders in laser scanning analysis (Fluoro Image Analyzer) could be enhanced: (1) $0.1 \%$ berberine hemisulfate for polyphenolics (Sigma B-3412), mounted in $0.1 \% \mathrm{FeCl}_{3} / 50 \%$ glycerol (Brundrett et al. 1988); (2) $0.1 \%$ berberine hemisulfate counterstained with $0.5 \%$ aniline blue (Aldrich 86, 102-2) (Brundrett et al. 1988); (3) $0.01 \%$ fluorol yellow 088 (Sigma F-5520) in polyethylene glycol 400 (Merck 8.07485) for lipids (Brundrett et al. 1991). Fluorescence of stained cork microtome cross sections in the Fluorescence Microscope was compared with autofluorescence (UV and blue excitation); microphotographs were taken with a Nikon Coolpix 4500 digital camera.

Image analysis

The evaluation of images was done by visual evaluation and by evaluation of transect lines. The transect lines were constructed with a special software developed in the Delphi 5 Enterprise (Borland) programming environment (Codegear, Scotts Valley, California, USA). This software was developed in University of Evora (Portugal). However, any software capable of resolving values of individual pixels would work as well (e.g., GRASS-open source GIS, module r.transect).

In the software the user is asked to mark beginning and end of the transect line and the program calculates the position of the pixels through which this line passes. These pixels are then read out from the original file and the values of RGB channels are displayed on a chart. In the case of images from the Fluoro Image Analyzer, only one channel was used, because it is a gray level image and RGB values are equal. 
If the spatial resolution of the pixel is known, year width can be easily measured by simply counting the pixels between the growth ring borders using software that permits such a task (ArcGIS, IDRISI, GRASS, etc.).

For delineating the individual rings a digital image with a pixel resolution of $42 \mu \mathrm{m}$ (visible light scan) or $10 \mu \mathrm{m}$ (autofluorescence scan) was used. Concerning the Nyquist sampling theorem (Unser 2000), this resolution is sufficient to detect anything with twice the size of this resolution, i.e., in this case anything which is bigger than 84 and $20 \mu \mathrm{m}$, respectively.

To test the reliability of the fluoro imager method to measure annual ring width, six measurements of annual growth from six trees from the same stand were compared as described for cross dating of annual rings in wood (Schweingruber 1988).

\section{Results and discussion}

Visibility of annual cork growth rings

Different methods to visualize growth ring borders in cross-sectional planes were compared.

In normal digital scans of polished cork cross-sectional planes ring-like structures were discernable but it was difficult to assign annual borders, especially in older parts of the cork sections (Fig. 1a). Low magnification bright

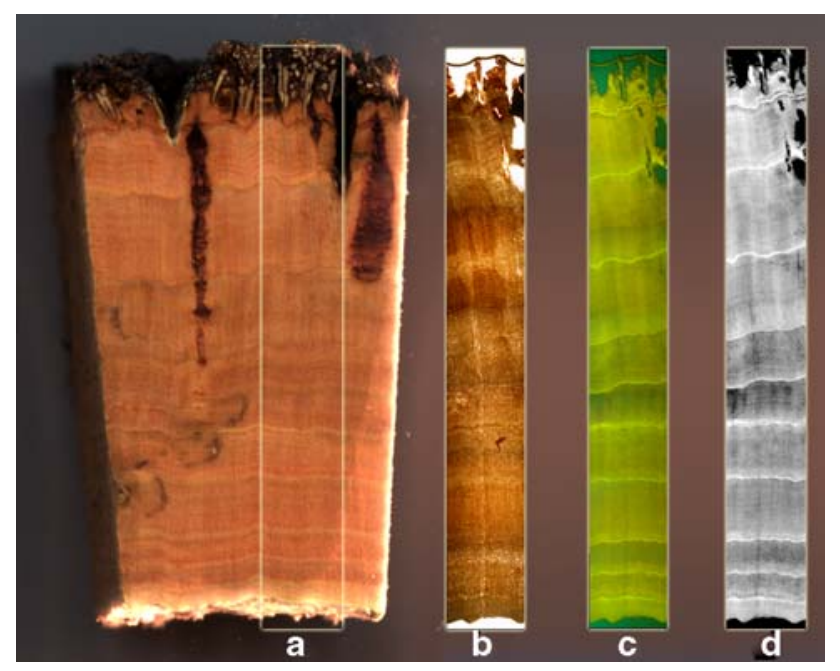

Fig. 1 Comparison of the visibility of growth rings in cork crosssectional planes under different light conditions. a normal digital scan of polished cork cross-sectional surface; b-d scans of microtome sections: b bright field micrograph, $\mathbf{c}$ autofluorescence scan (epifluorescence microscope, blue excitation), $\mathbf{d}$ laser scan, blue excitation. Bottom of the scan $=$ youngest cork, top of the scan $=$ oldest cork. Scans (b) and (c) were prepared from a series of microphotographs taken with $125 \times$ microscope magnification and combined to a complete scan by software Adobe Photoshop CS2 field micrographs of microtome sections did not improve the detectability (Fig. 1b). The difficulties in the delineation process of annual rings are evident, because no common rule could be followed. For example if one would start to mark the bottom of the white lines in the youngest part (here at bottom) of the cork cross-sectional plane, one would find no distinct white lines in the middle of the polished cork piece. Also the question arises where to mark the end of the growing season, at the bottom of the white line or at its top? These are the most likely reasons for the high uncertainty in annual growth ring measurements faced in the visible light.

In contrast to normal scans or light microcopy, delineation of growth ring borders in microtome sections via autofluorescence (epifluorescence microscope or laser scan with blue excitation) was excellent (Fig. 1c, d). Each growth ring border was marked by significantly higher autofluorescence. The expected number of nine annual rings was unambiguously detected (Fig. 1c, d). Preparing autofluorescence scans with the Fluoro Image Analyzer is a quick and easy method as compared to the use of microphotographs from the epifluorescence microscope. The spatial resolution of $10 \mu \mathrm{m}$ in the Fluoro Image Analyzer is sufficient to show the growth ring boundaries as precise as in autofluorescence scans obtained by the use of an epifluorescence microscope.

\section{Visibility of growth ring border-structural basis}

To find out if the line of intense autofluorescence marked the end of annual growth, we analyzed the cell structure at higher microscope magnification; the cell size should be significantly diminished at the end of the growth phase (Pereira et al. 1987; Fortes et al. 2004).

In Fig. 2a, a cork cross section with a clearly visible annual ring boundary displaying enhanced autofluorescence is shown. Figure $2 b$ shows the same part of the cork cross section in the light microscope and indicates that in the area of enhanced autofluorescence cork cells are smaller in radial extension. As the cork cambium is located towards the bottom of the microphotograph this means that this line of high autofluorescence corresponds to the end of the vegetation period. The new growth period starts with cork cells of lower autofluorescence and larger in radial extension. Pereira et al. (1987) and Fortes et al. (2004) already observed that cells produced in the early growing season are wider and have thinner walls than those produced in the late growing season. Thus, the structure of the annual ring boundary of cork is comparable to that in conifer wood (see Schweingruber 1988). Figure 2a shows that the very high autofluorescence of the last formed late cork cells is followed by a considerably lower autofluorescence of the first formed early cork cells. This allows the 
Fig. 2 Anatomy of cork cross sections; a, c autofluorescence with blue excitation, $\mathbf{b}, \mathbf{d}$ light microscopy. a and b Growth ring border marked by an arrow. The lower part of the microphotograph is towards the cork cambium. d Cells with entrapped air and cell wall foldings show enhanced wall autofluorescence (c)
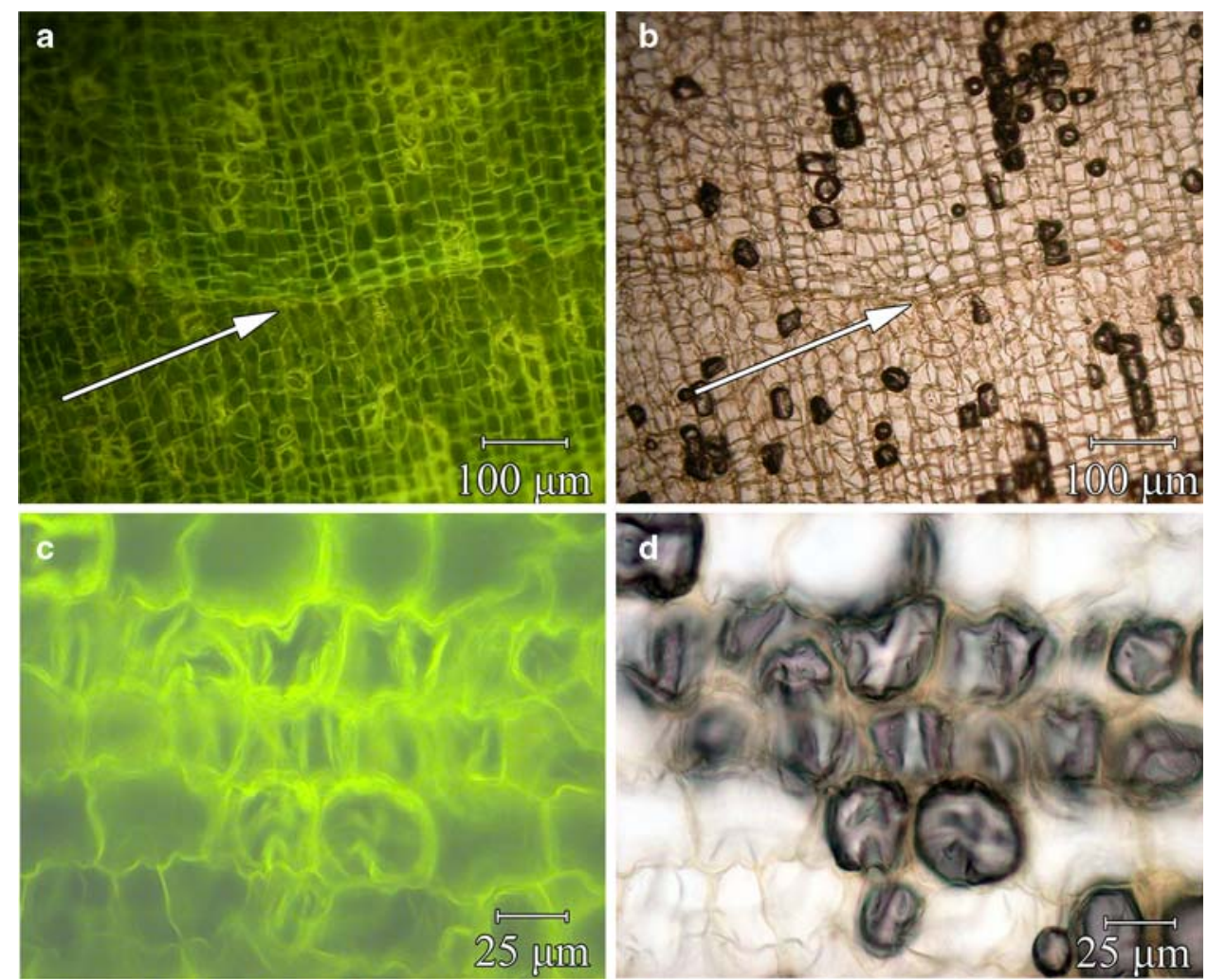

precise delineation of the growth ring border despite of changes in autofluorescence in the rest of the growth ring (Fig. 1c, d) and of high autofluorescence sometimes visible in scattered stone cells or in radial rows of cork cells (Fig. 2a), showing air inclusions in the normal light (Fig. 2b). High microscope magnification shows that these cells are heavily corrugated cork cells, as shown in the SEM by Pereira et al. (1987), exhibiting higher autofluorescence per cell area (Fig. 2c) due to cell wall infoldings and reflection of the fluorescent light at the air encaged in these cells (Fig. 2d).

Visibility of growth ring border-chemical basis

Fluorescence microscopic investigations of cork cross sections clearly show that the growth ring border can be made visible by enhanced autofluorescence with UV excitation (Fig. 3a) and with blue excitation (Fig. 3b). Autumn cork shows much higher autofluorescence than cork formed early in the year. The border between autumn cork and early summer cork is sharp, based on cell size and intensity of autofluorescence. To get microphotographs of comparable quality, the exposure time under blue excitation was 4-times longer than under UV excitation. Obviously, the blue excitation fluorescence is much weaker but strong enough to give good results in the fluorescence microscope and in the Fluoro Image Analyzer.
Autofluorescence upon UV excitation is an indication for cell wall modifications by polyphenolics, i.e., lignin (Willemse 1981), aromatic suberin polymers (Bernards and Lewis 1998) or other aromatic compounds. Polyphenolics have been extracted from reproductive cork of Quercus suber (Pereira 1988), with suberin being present at a considerably higher concentration than that of lignin. Viewing the UV fluorescence of autumn cork cells with high microscopic magnification one can see that the compound middle lamella (and adjacent secondary wall) shows only weak autofluorescence in comparison to the thick inner secondary wall (Fig. 3e).

Histochemical investigations were performed to show which polyphenolic substance is mainly responsible for the enhanced autofluorescence at the growth ring border and whether the visibility of cork rings upon blue excitation can even be enhanced by different histochemical treatments.

Staining cork cross sections with berberine hemisulfate, a fluorochrome preferentially binding to lignin and suberin (Brundrett et al. 1988), significantly enhanced the fluorescence signal over the whole cross section, but resulted in decreased contrast between rings and intermittent areas (Fig. 3c). Counterstaining with aniline blue again enhanced the visibility of the growth ring border in comparison to pure visibility upon staining with berberine hemisulfate (Fig. 3d). Aniline blue quenches the berberine fluorescence at places of unspecific staining or at cell walls with low 
Fig. 3 Visibility of growth ring borders in cork cross sections after different staining procedures. Fluorescence images show early cork (left side) and late (autumn) cork (right side) in the microphotographs. a Excellent visibility; autofluorescence, UV excitation, $1 / 30 \mathrm{~s}$ exposure time, b Excellent visibility; autofluorescence, blue excitation, $1 / 8 \mathrm{~s}$ exposure time, c Poor visibility after staining with fluorochrome berberine hemisulfate for lignin and suberin; UV excitation, exposure time $1 / 30 \mathrm{~s}$,

d Reestablished visibility when berberine hemisulfate staining was followed by counterstaining with aniline blue; UV excitation, exposure time $1 / 8 \mathrm{~s}$, e Autofluorescence of autumn cells in detail; UV excitation. f Growth ring border visible, but visibility much reduced after staining for suberin with lipid fluorochrome fluorol yellow 088; blue excitation, exposure time $1 / 30$ s. $\mathbf{g}$ and h Growth ring border cells in detail, after staining for suberin with lipid fluorochrome fluorol yellow 088, g UV excitation. f, blue excitation, $1 / 15 \mathrm{~s}$ exposure time. Arrows indicate the growth ring border
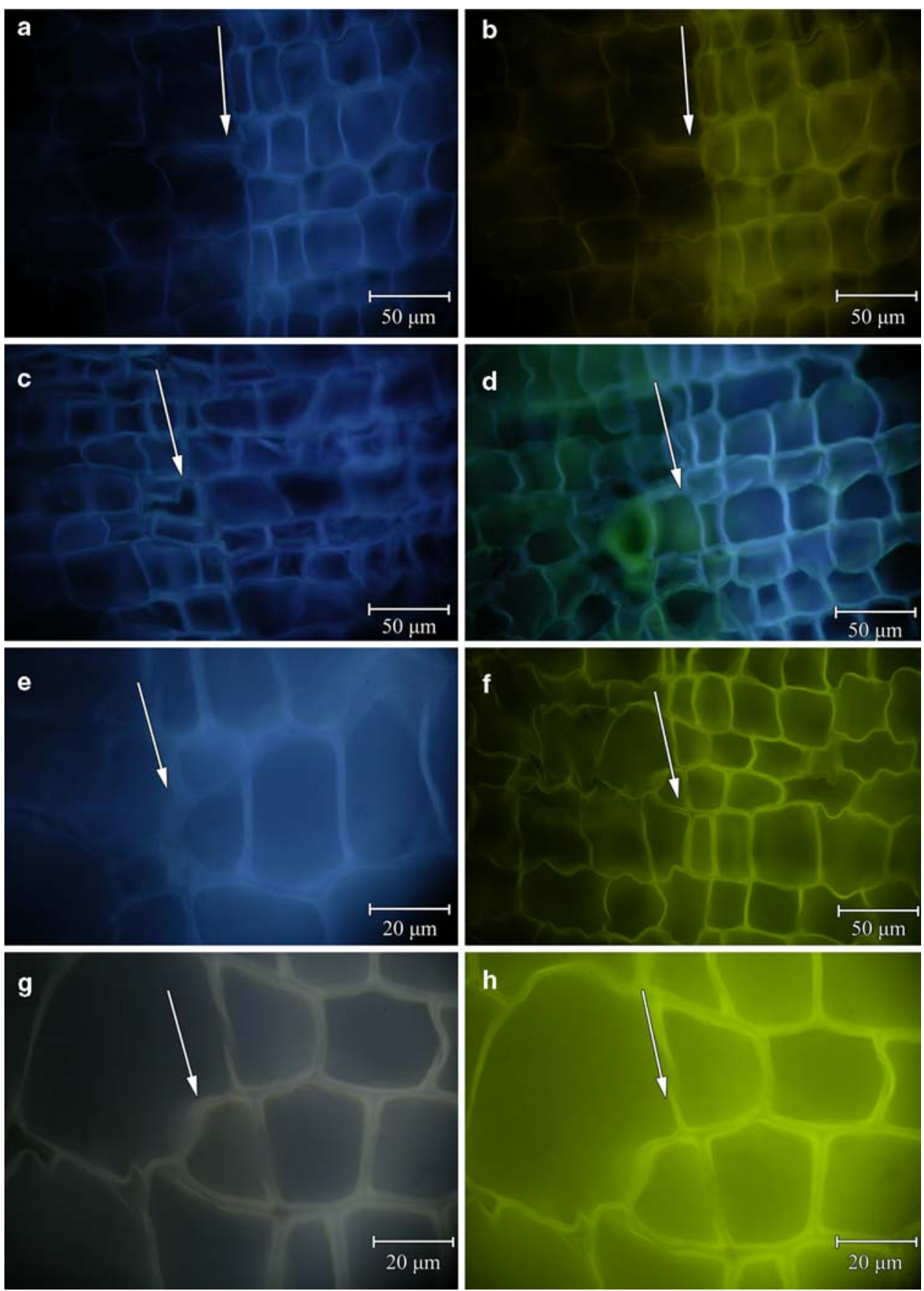

content of polyphenolics (Brundrett et al. 1988). The recommended excitation light for berberine hemisulfate staining is UV (Fig. 3c) and not blue as used in the Fluoro Imager; Brundrett et al. 1988 stated that the berberinebased fluorescence is more widespread with blue excitation than with UV. Therefore, it was expected that the visibility of the growth ring borders in the Fluoro Image Analyzer would be even worse than shown in Fig. 3c upon UV excitation in the fluorescence microscope.

Staining cork cross sections with Fluorol yellow 088, a fluorochrome that binds to lipid components of suberin
(Fig. 3f-h) indicates the presence of suberin in walls of summer cork and autumn cork. Both show only weak fluorescence in the compound middle lamella region (Fig. 3g, h), probably related to lignin. Lignification of the compound middle lamella of Quercus suber was already described by von Höhnel (1877). Both, early cork and late cork cells show an intense yellowish fluorescence in the secondary walls, deriving from suberin. Sitte (1962) analyzed this cell wall region by electron microscopy and found it is composed of suberin lamellae. However, this suberized part of the wall was much thicker in the smaller 
autumn cork cells (right side in Fig. 3g, h) than in the larger early summer cork cells (left side in Fig. $3 g, h$ ). Thus, enhanced autofluorescence in cork cross sections of the autumn cork is not only due to smaller cells yielding higher areas of modified cell walls, but also clearly comes from the thicker suberin layer in autumn cork cells. Smaller autumn cells enhanced the effect, especially in microtome sections because surface views on walls are more often visible, whereas from the much larger summer cork cells mainly cross-sectional walls can be seen (Fig. 3a, b).

Staining the cork cross sections with fluorol yellow 088 made the delineation of the annual rings more difficult than in unstained cork cross sections (compare Fig. 3b, f). Upon staining with fluorol yellow 088 the overall fluorescence in the cork cross section was significantly increased but the contrast between growth ring borders and the tissue in between decreased. As seen in the fluorescence microscope under blue excitation (Fig. 3f, h) the fluorescence was more widespread than under UV (Fig. 3g). The excitation light recommended by Brundrett et al. (1991) for this dye is UV and not blue as used in the Fluoro Image Analyzer. An overall increase of fluorescence as found here indicated that suberin can be found in all cork cells; differences in concentration per cross-sectional area, however, could only be made visible by choosing an adequate exposure time, which, however, is not possible in the Fluoro Image Analyzer.

Thus the fluorescence micrographs suggest that staining of cork microtome sections for polyphenolic substances or for suberin with fluorescent dyes will not enhance the visibility of the growth rings in the Fluoro Image Analyzer as compared to analysis of unstained microtome sections.

Measurements of annual growth distances based on autofluorescence and normal line scans

The preparation of microtome sections for evaluation of annual cork rings in the fluoro imager is time consuming. To investigate whether polished cross-sectional surfaces of cork pieces and microtome sections give similar results for growth ring borders in the Fluoro Image Analyzer, different methods to obtain laser scans from such cork pieces were tested (see "Material and methods"). Smoothing the cross-sectional plane with a microtome knife was time consuming, but gave excellent results (Fig. 4). The easiest procedure with acceptably good results proved to be sand paper polishing of dry cork oak pieces and subsequent wetting for laser scanning.

To document the improvement of growth ring evaluation with the laser scanning method, laser scans with blue excitation were compared with normal digital scans of cork pieces. Figure 4 shows transect lines through a scanned cork sample (cross-sectional surface). The reflectance of the cork in normal light was compared with that in laser light using the Fluoro Image Analyzer. The images taken by visible light scan and images from Fluoro Imager were orthorectified in order to get the analyzed cork samples overlaid. This allowed to extract the transect line at the same place of the cork surface.

Most of the peaks obtained in the laser light corresponded to valleys in the visible light. Ring brightness is inversely related to ring density (Sheppard 1999). In the different spectra (red, green, blue) in cork these regions of minimum reflectance were most distinct in the red light. Images of pine wood taken with a flatbed CCD line scanner, however, showed the highest correlation of maximum latewood density with minimum blue light reflectance (McCarroll et al. 2002; Campbell et al. 2007). This result corresponds with some of our visible light reflectance results on cork, at places with higher late cork density. However, some of the annual ring peaks obtained from cork in the laser light corresponded to peaks in visible light (e.g., border 99-00; Fig. 4), and within the cork growth ring several peaks of visible light reflectance, valleys of minimum visible light reflectance or unspecific scattering could be seen. This underscores the lack of a common rule which could help to delineate the annual rings in normal light, as differences in density and color may be visible within growth rings of sand polished cross-sectional surfaces of an untreated cork piece. It has to be taken into consideration that in case of determination of maximum late wood density by minimum blue reflectance in pine wood (McCarroll et al. 2002) thin $(1.25 \mathrm{~mm})$ laths had to be extracted to remove resins and heartwood substances prior to scanning the sanded smooth wood cross-sectional surface. To use reflected-light image analysis in annual ring determination, extraneous color variation in wood (Sheppard 1999) and probably also in cork must be overcome.

\section{Evaluation of visibility of annual growth rings}

To document the strength of the method, six radial transect lines through laser scans of sand paper polished, wetted cork cross-sectional planes (cork pieces from six trees) were combined in one chart (Fig. 5). The trees were all from the same stand (permanent research plot) and were debarked the same year; however, the stand is quite irregular, with slopes and different expositions. Differences in annual ring width might be due to stand differences, however, the majority of the transect lines indicates a very intense annual cork growth in 2001, a year with excessive summer rain (Instituto de Meteorologia Portugal, IP Portugal) thus demonstrating that cross dating within a stand is possible.

Table 1 shows the percentage of samples in classes of visibility of individual rings. In comparison to the 
Fig. 4 Chart of radial transection lines (year 20041994) through the same cork cross-sectional plane (straightened with a microtome knife) in different parts of the light spectrum (reflection in red, green, blue: $\mathrm{R}, \mathrm{G}, \mathrm{B}$; normal digital scan; bottom line $=\mathrm{B}$; second line from the bottom $=\mathrm{G}$, third $=\mathrm{R}$ ) and in an autofluorescence scan taken with the Fluoro Image Analyzer (top line). Representative results

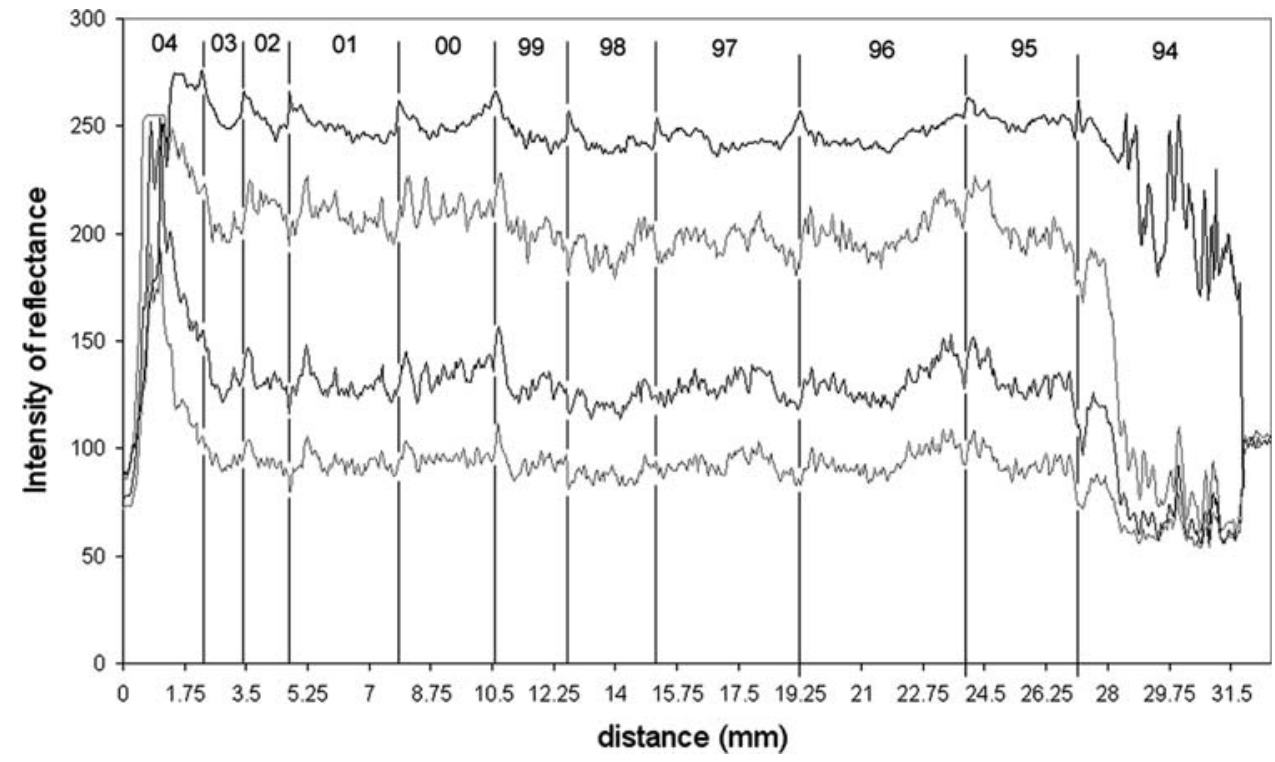

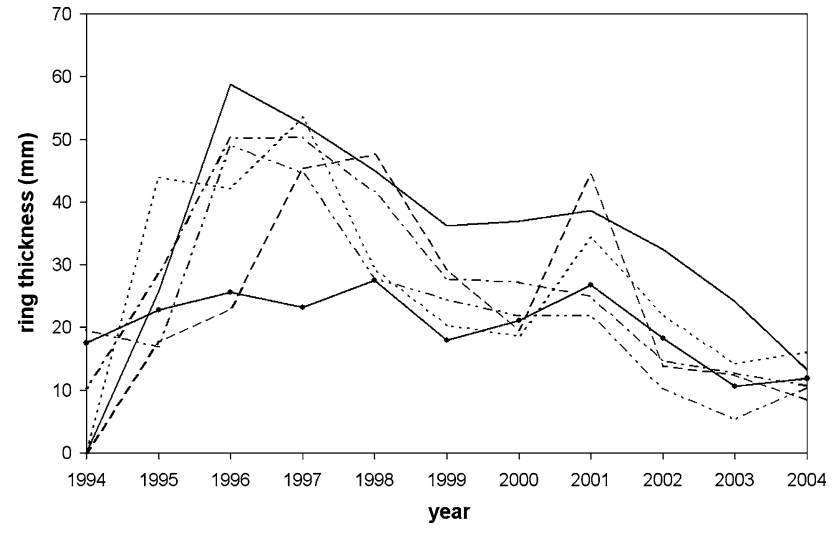

Fig. 5 Radial growth (annual ring width in $\mathrm{mm}$ ) from year 1994 to year 2004 (six measurements from six trees) as measured in laser scans of sand paper polished, wetted cork cross-sectional planes. The trees were all from the same stand and were debarked the same year

previously demonstrated classification in normal light scans (Table 1) the visibility of growth rings is significantly improved in the Fluoro Image Analyzer. There was no sample rated as very bad and the percentage of bad ratings is decreased while the percentage of very good ratings is increased.

The $\chi^{2}$ test (Excel 2003; Microsoft Corporation, Redmond, Washington, USA) was done to evaluate differences between the visibility of annual rings in normal light and by means of the new laser scan method. Two sample sets acquired by normal scanning (group $1, n=694$, group 2 , $n=508$ samples) each were compared with the new method ( $n=64$ samples). The hypothesis was tested that the relative distributions of visibility were equal for the new and the conventional method.

The value of the $\chi^{2}$ statistic per pair group, normal light scans compared to new laser scans, is 25.24 for group 1 and
Table 1 Evaluation of visibility of cork rings in scans under normal light in two different datasets (Group $1=694$ samples; Group $2=508$ samples) and by two different research groups (Surovyunpublished data) compared with evaluation of visibility of annual cork rings in the dataset of 64 samples (from 30 trees) scanned with the new fluoro imager method

\begin{tabular}{llllc}
\hline Group & \multicolumn{4}{l}{$\begin{array}{l}\text { Visibility classification of annual rings; \% in data } \\
\text { set }\end{array}$} \\
\cline { 2 - 5 } & VG & G & B & VB \\
\hline $\begin{array}{l}\text { (1) visible light } \\
n=694\end{array}$ & 5.8 & 61.8 & 28.0 & 4.4 \\
$\begin{array}{l}\text { (2) visible light } \\
n=508\end{array}$ & 9.4 & 34.1 & 35.2 & 21.3 \\
$\begin{array}{l}\text { (3) fluoro imager } \\
n=64\end{array}$ & 45.3 & 48.5 & 6.2 & 0.0 \\
\end{tabular}

Cork pieces with sand paper polished, wetted cross-sectional surface were investigated. The percentage of cork samples with very good (VG), good (G), bad (B), and very bad (VB) visibility of annual rings is shown

33.75 for group 2. The critical value of $\chi^{2}$ for three degrees of freedom and probability level of significance $(P \leq 0.05)$ was 7.82. Since the $\chi^{2}$ statistic was above this threshold the null hypothesis that the distributions are equal, had to be rejected. This supports the significantly different results given by the two methods.

\section{Conclusions}

Cork producers are interested in obtaining data about annual growth increments of Quercus suber reproductive cork. It is obvious that delineation of growth rings in cork using normal light is usually not easy; only about $10 \%$ of 
the data can be used with $100 \%$ confidence to evaluate the annual growth. In this study a new method has been developed to measure the annual increment of cork with high confidence. Annual rings can be delineated from autofluorescence images taken from cork cross sections in the fluorescence microscope with UV or blue excitation. However, they also can be excellently delineated in a laser based fluorescence imager with blue excitation using water wetted dry cork pieces on a polished cross-sectional plane, thus providing a method for rapid and accurate identification of cork growth rings.

Smaller autumn cork cells in combination with a very thick suberin layer in the cell walls resulted in an enhanced suberin autofluorescence signal per cork cross-sectional area at the end of vegetation season.

Exploiting suberin autofluorescence by fluorescence imaging, this new kind of image improved the percentage of good and very good samples for measuring annual growth, thus enhancing the data available for cork growth modeling. In future, this method can be applied to evaluate silvicultural practices in cork oak stand management (Cañellas and Montero 2002). It is of economic value to know the rates of growth and the environmental conditions that favor the greatest (or highest quality) growth of cork. It is known that climate influences cork cambium activity and yearly cork increment (Caritat et al. 2000); this could also be demonstrated for excessive rain in 2001 by a radial series of annual ring widths obtained with the new Fluoro Image Analyzer method from six trees of the same stand. In the cork samples investigated so far, intra-annual variations in autofluorescence did not hinder the delineation of the growth ring border by autofluorescence, as the autofluorescence peak at the border from last late cork to first early cork is very steep.

Whether the new laser based fluorescence imager method would be applicable to sand paper polished crosssectional surfaces of wood will depend on the existence of a distinct enhanced autofluorescence at the growth ring borders. In wood autofluorescence upon blue light excitation is mainly due to lignin (Donaldson et al. 2001).

Acknowledgments We appreciate the skillful technical assistance of Gabriele Lehmann, LARI (Laboratory of Isotopes of University of Göttingen). The authors would also like to acknowledge the funding from program AGRO, from Portuguese Ministry of Agriculture, Rural development and Fishery (project Agroreg), through which the cork samples were obtained and a Ph.D. scholarship to PS provided by the EU via the Marie Curie Training Site "Wood Biotechnology".

Open Access This article is distributed under the terms of the Creative Commons Attribution Noncommercial License which permits any noncommercial use, distribution, and reproduction in any medium, provided the original author(s) and source are credited.

\section{References}

Bernards MA, Lewis NG (1998) The macromolecular aromatic domain in suberized tissues: a changing paradigm. Phytochemistry 47:915-933

Brundrett MC, Enstone DE, Peterson CA (1988) A berberine-aniline blue fluorescent staining procedure for suberin, lignin and callose in plant tissue. Protoplasma 146:133-142

Brundrett MC, Kendrick B, Peterson CA (1991) Efficient lipid staining in plant material with Sudan red 7B or Fluorol Yellow 088 in polyethylene glycol-glycerol. Biotech Histochem 66:111116

Campbell R, McCarroll D, Loader NJ, Grudd H, Robertson I, Jalkanen R (2007) Blue intensity in Pinus sylvestris tree rings: developing a new palaeoclimate proxy. The Holocene 17:821828

Cañellas I, Montero G (2002) The influence of cork oak pruning on the yield and growth of cork. Ann For Sci 59:753-760

Caritat A, Molinas M, Gutierrez E (1996) Annual cork-ring width variability of Quercus suber L. in relation to temperature and precipitation (Extremadura, southwestern Spain). For Ecol Manage 86:113-120

Caritat A, Guitierrez E, Molinas M (2000) Influence of weather on cork-ring width. Tree Physiol 20:893-900

Donaldson L, Hague J, Snell R (2001) Lignin distribution in coppice poplar, linseed and wheat straw. Holzforschung 55:379-385

Evert RF (2006) Esau's plant anatomy. Wiley, Hoboken, New Jersey, USA

Fortes MA, Rosa ME (1992) Growth stresses and strains in cork. Wood Sci Technol 26:241-258

Fortes MA, Rosa ME, Pereira HA (2004) Cortiça. Editora IST Press, Lisbon

Gonçalvez E (2000) The cork report: a study of the economics of cork. RSPB, Sandy, Bedfordshire

Guay R, Gagnon R, Morin H (1992) Mac DENDRO, a new automatic and interactive tree ring measurement system based on image processing. In: Bartholin TS, Berglund BE, Eckstein D, Schweingruber $\mathrm{FH}$, Eggertson $\mathrm{O}$ (eds) Tree rings and environment. LUNDQUA Report, vol 34. Lund, Sweden, pp 128-131

Kitin PB, Fujii T, Abe H, Funada R (2004) Anatomy of the vessel network within and between tree rings of Fraxinus lanuginosa (Oleaceae). Am J Bot 91:779-788

McCarroll D, Pettigrew E, Luckman A, Guibal F, Edouard JL (2002) Blue reflectance provides a surrogate for latewood density of high-latitude pine tree rings. Arct Antarct Alp Res 34:450-453

Montero G, Torres E, Cañellas I, Ortega C (1996) Modelos para la estimacion de la produccion de corcho en alcornocales. Invest Agr Sist Recur For 5:97-127

Müller U, Gindl W, Teischinger A (2003) Effects of cell anatomy on the plastic and elastic behaviour of different wood species loaded perpendicular to grain. IAWA J 24:117-128

Neves AMC (2001) A utilização de métodos de Análise de Imagem na Determinação de Classes de Qualidade da Cortiça. Diploma thesis, Universidade de Évora, Portugal

Park W-K, Telewski FW (1993) Measuring maximum latewood density by image analysis at the cellular level. Wood Fiber Sci 25:326-332

Pereira H (1988) Chemical composition and variability of cork from Quercus suber L. Wood Sci Technol 22:211-218

Pereira H, Rosa ME, Fortes MA (1987) The cellular structure of cork from Quercus suber L. IAWA Bull 8:213-218

Pereira H, Lopez F, Graça J (1996) The evaluation of the quality of cork planks by image analysis. Holzforschung 50:111-115 
Quilho T, Lopes F, Pereira H (2003) The effect of tree shelter on the stem anatomy of cork oak (Quercus suber) plants. IAWA J 24:385-395

Ribeiro NA, Oliveira AC, Pretsch H, Surový P (2003) Growth simulation and sustainability of cork oak stands. In: Amaro A, Reed D, Soares P (eds) Modelling forest systems. CABI Publishing, Wallingford, UK, pp 259-267

Schweingruber FH (1988) Tree rings: basics and applications of dendrochronology. Kluwer, Dordrecht

Schweingruber FH (1990) Radiodensitometry. In: Cook ER, Kairiukstis LA (eds) Methods of dendrochronology: applications in the environmental science. Kluwer, Dordrecht, pp 55-62

Sheppard PR (1999) Overcoming extraneous wood color variation during low-magnification reflected-light image analysis of conifer tree rings. Wood Fiber Sci 31:106-115

Sheppard PR, Graumlich LJ (1996) A reflected-light video imaging system for tree ring analysis of conifers. In: Dean JS, Meko DM, Swetnam TW (eds) Tree rings, environment and humanity. Radiocarbon 1996. Proceedings of the International conference,
17-21 May 1994, Tucson Ariz, Department of Geosciences, University of Arizona, Tucson, USA, pp 879-889

Sitte P (1962) Zum Feinbau der Suberinschichten im Flaschenkork. Protoplasma 54:555-559

Tomé M, Coelho MB, Almeida A, Lopes F (2001) O modelo SUBER. Estrutura e equações utilizadas Relatórios técnico-científicos do GIMREF $n^{\circ}$ 2/2001. Centro de Estudos Florestais, Instituto Superior de Agronomia, Lisboa, Portugal

Unser M (2000) Sampling-50 years after Shannon. Proc IEEE $88: 569-587$

Von Höhnel (1877) Über den Kork und verkorkte Gewebe überhaupt. Sitz-Ber Akad Wiss Wien 76:507-562

Willemse MTM (1981) Changes in autofluorescence of lignin. In: Robinson DG, Quader H (eds) Cell Walls '81. Wissenschaftliche Verlagsgesellschaft, Stuttgart, pp 242-250

Wimmer R (2002) Wood anatomical features in tree rings as indicators of environmental change. Dendrochronologia 20:2136 